\title{
Relationship between intracellular pathogens Toxoplasma gondii and Borrelia burgdorferi infections and migraine
}

Murat Yilmaz ${ }^{1}$, Aysen Tugba Canbasoglu Yilmaz ${ }^{2}$, Handan Teker ${ }^{1}$, Sule Aydin Turkoglu ${ }^{1}$, Serpil Yildiz ${ }^{1}$

${ }^{1}$ Department of Neurology, Bolu Abant Izzet Baysal University, School of Medicine, Bolu, Turkey

${ }^{2}$ Department of Neurology, Bolu Private Cagsu Hospital, Bolu, Turkey

\section{ABSTRACT}

Aim: In this study, the serological values of our patients followed up with a diagnosis of migraine were compared with the results of healthy controls in terms of possible association with intracellular pathogens, Toxoplasma gondii and Borrelia burgdorferi.

Methods: Fifty patients with migraine, randomly selected among migraine patients without any additional disease, who applied to Bolu Abant Izzet Baysal Training and Research Hospital between January 1, 2015 and August 31, 2019 were included in the study. Fifty subjects without headache were included as control group. The history of infectious diseases of the patient and control groups (Toxoplasma gondii, Borrelia burgdorfericausing Lyme disease) was determined by serological diagnostic methods.

Results: The study group consisted of 64 women with a mean age of $45.5 \pm 13.1$ (15-76) years. Migraine and control groups were found to be similar in terms of age $(\mathrm{p}=0.059)$ and gender $(\mathrm{p}=0.211)$ distributions. The frequency of Toxoplasma gondii positivity in the migraine group was $28 \%(\mathrm{n}=14)$ and $10 \%(\mathrm{n}=5)$ in the control group. The frequency of Lyme was $19.6 \%(n=11)$ in the migraine group and $14.3 \%(n=8)$ in the control group. The frequency of Toxoplasma gondii positivity was statistically significantly higher in the migraine group $(\mathrm{p}=0.022)$, while the frequency of Lyme was found to be similar in the migraine and control groups $(\mathrm{p}=0.450)$. Conclusion: The results of our study suggest that there are statistically significant differences between migraine and control groups only in terms of Toxoplasma gondii positivity rates, not Lyme. However, we believe that larger sample studies are needed to determine the detailed relationship between migraine and Toxoplasma gondii infection.

Key words: Migraine disorders, Toxoplasma gondii, Borrelia burgdorferi, Lyme, serum immunoglobulins.

$\triangle$ Dr. Murat Yilmaz

Department of Neurology, Bolu Abant Izzet Baysal University, School of Medicine, Bolu, Turkey

E-mail: dryilmazmurat@gmail.com

Received: 2021-04-16/Revisions: 2021-05-25

Accepted: 2021-05-29 / Published online: 2021-07-01

\section{Introduction}

Migraine is a form of recurrent headache experienced by approximately $10 \%$ of the population, with a 3:1 female-to-male ratio [1].
It is renowned for severely disabling headache attacks which last 4-72 hours, are often unilateral, and are exacerbated by routine physical activity. These attacks can also be associated with nausea, photophobia or phonophobia [2].

Many factors, like foods, psychosocial stress, lifestyle factors and smoking have been suggested to trigger migraine [3]. More interestingly, it has been emphasized that some 
infections, such as Toxoplasma gondii (causing Toxoplasmosis), can be associated with migraine and it has also been reported that some infections can mimic the clinical features of migraine [4-6]. Therefore, screening patients diagnosed with migraine in terms of these infections may be beneficial for diagnosis and treatment in migraine. Although the relationship between Toxoplasma gondii and migraine has been studied relatively more frequently, there are very few studies examining the relationship between migraine and other diseases caused by intracellular pathogens, such as Lyme [5,6]. Lyme disease, usually caused by infection with the spirochete Borrelia burgdorferi, is a multisystem disease caused by the body's immune response to infection [7]. These patients may present with physical findings such as headache, meningismus and cranioneuropathy as a sign of aseptic meningitis $[7,8]$.

In this study, the serological values of our patients followed up with a diagnosis of migraine were compared with the results of healthy controls in terms of possible association with intracellular pathogens, Toxoplasma gondii and Borrelia burgdorferi.

\section{Materials and methods}

\section{Patient and control groups}

In this study, patients with migraine who had applied to the Neurology Clinic of Bolu Abant Izzet Baysal Training and Research Hospital, between January 1, 2015 and August 31, 2019 were included. A healthy control group comprised of patients who had applied to the clinic in the study period were also included.

Between the specified dates, a total of 50 patients with migraine attended follow-up or were newly diagnosed. Additionally, patients without migraine who had been admitted for other symptoms but were not diagnosed with any neurological condition were included as healthy controls. Among these, patients with any other chronic diseases, history of surgery or malignancy, those with other neurological or psychiatric diagnoses, and individuals who refused to participate in the study were excluded from the analyses. A final total of 50 patients with migraine and 50 controls had undergone serological analyses for Toxoplasmosis and Lyme.

Necessary permissions were obtained from the Clinical Research Ethics Committee of Bolu Abant Izzet Baysal University to conduct the study. (Approval number: 2020/245, Approval date: 13/10/2020) and all the patients were informed about the study and their written informed consents were obtained.

\section{Serological method}

The infectious disease history of the patient and control groups (Toxoplasma gondii, Lyme) was determined by serological diagnostic methods. A commercial ELISA kit (Bio-Rad, France) was used for the detection of Toxoplasma gondii $\mathrm{IgG}$ and IgM antibodies. The presence of Lyme disease serology was assessed via ELISA (Anti-Borrelia IgG and IgM Generic Assay, Germany) in serum samples. All detection procedures were performed according to the manufacturer's instructions. Presence of either or both IgG and IGM antibodies was accepted seropositive

\section{Sample size and statistical analysis}

For the sample size, it was determined that at least 50 subjects should be included in each group according to power analysis performed with the following parameters: $5 \%$ error margin, $80 \%$ power, an expected odds ratio of 3 with a $50 \%$ frequency distribution of infection.

The SPSS version 20 program was used for the analysis of all data. The Shapiro-Wilk test was 
used to evaluate compliance with normal distribution. For continuous data, median, lowest and highest values (min-max) and/or mean \pm standard deviation were preferred for the description of data, with respect to normality of distribution. The Mann Whitney U or Student's t-test was used for the comparison of continuous data between groups in the presence of non-normal and normal distribution, respectively. Pearson Chi-Square test was used for the comparison of categorical data. The $p<0.05$ threshold was defined as the level of significance.

\section{Results}

The study group consisted of 64 females and mean age was $45.5 \pm 13.1$ (min-max: 15-76) years. The migraine and control groups were similar in terms of age $(\mathrm{p}=0.059)$ and gender distribution $(p=0.211)$.

Toxoplasma gondii positivity was detected in $14(28 \%)$ patients in the migraine group and in 5 (\%10) subjects in the control group. The frequency of Toxoplasma gondii positivity was statistically significantly higher in the migraine group compared to the control group $(p=0.022)$.

Lyme positivity was detected in $11(19.6 \%)$ patients in the migraine group and in $8(14.3 \%)$ subjects in the control group. There was again no significant difference between the groups $(p=0.450)($ Table 1$)$.

\section{Discussion}

The present study, in which we aimed to determine whether there were relationships between migraine presence and intracellular pathogens, demonstrated that there was no difference between the migraine and control groups in terms of Lyme positivity frequency. However, of note, the frequency of Toxoplasma gondii positivity was higher in the migraine group compared to controls.

In previous studies, Toxoplasma gondii has been shown to be a neurotrophic pathogen and is associated with neurological and neuropsychiatric symptoms [9-11]. In addition, the relationship between migraine, headache and Toxoplasma gondii has also received relatively high interest $[5,8,12]$. It has been

Table 1. Age and gender characteristics and infection positivity frequencies of the study.

\begin{tabular}{|c|c|c|c|}
\hline Parameters & $\begin{array}{c}\text { Control group } \\
\mathbf{n}=\mathbf{5 0}\end{array}$ & $\begin{array}{l}\text { Migraine group } \\
\quad \mathbf{n}=\mathbf{5 0}\end{array}$ & $p$-value \\
\hline Age, years, mean \pm SD & $44.3 \pm 15.23$ & $47.5 \pm 10.8$ & 0.059 \\
\hline \multicolumn{4}{|l|}{ Gender, n (\%) } \\
\hline Female & $29(58.0 \%)$ & $35(70.0 \%)$ & \multirow[t]{2}{*}{0.211} \\
\hline Male & $21(42.0 \%)$ & $15(30.0 \%)$ & \\
\hline \multicolumn{4}{|l|}{ Toxoplasma gondii, n (\%) } \\
\hline Negative & $45(90.0 \%)$ & $36(72.0 \%)$ & \multirow[t]{2}{*}{0.022} \\
\hline Positive & $5(10.0 \%)$ & $14(28.0 \%)$ & \\
\hline \multicolumn{4}{|l|}{ Lyme (Borrelia burgdorferi), n (\%) } \\
\hline Positive & $6(12.0 \%)$ & $10(20.0 \%)$ & 0.275 \\
\hline
\end{tabular}


reported that this infection affects the levels of specific cytokines, causing edema in the brain, which may manifest as headaches $[13,14]$. In addition, in a study by Koseoglu et al., it was reported that Toxoplasma gondii was associated with migraine and was concluded that this infection may cause a neuroinflammatory process in the brain, thereby triggering migraine [8]. In a study comparing 105 patients with headache and 105 non-headache subjects, it was reported that the case and control group were similar in terms of Toxoplasma seropositivity [15]; however, interestingly, the level of IgG for Toxoplasma gondii was suggested to be associated with headache-even when the patient group included other types of headaches in addition to migraine (39 patients with migraine in the 105 subjects). Since this infection is very prevalent among humans, has a chronic characteristic in an estimated $30 \%$ of individuals [16] and the fact that the infection may persist in the brain [17], have supported the rationale of studies aiming to determine a relationship (if any) between headache and Toxoplasma gondii infection. One such study even suggested the introduction of serological testing for Toxoplasma gondii, after demonstrating that $11 \%$ of children with recurrent headaches had IgG positivity [12]. In a study from Brazil, wherein 261 cases with acute toxoplasmosis were investigated, headache frequency was reported to be the second most frequent symptom (after fever), and perhaps more interestingly, the distribution among sexes demonstrated a female-to-male ratio of 2.1 to 1 [18]. In the current study, to support the information in the literature, the frequency of Toxoplasma gondii positivity was significantly higher in patients with a diagnosis of migraine. We believe that these results indicate that the relationship between migraine and toxoplasmosis warrants further investigation, preferably in population-based studies.

When Borrelia burgdorferi, the cause of Lyme disease, reaches the cerebral or spinal vessels, it attaches to endothelial cells. It has been reported that the direct and indirect effects of B.burgdorferi on the nervous system play a role in the formation of neuroborreliosis [19]. In a previous study, it was reported that $B$. burgdorferi invaded human neuronal and glial cells, remained alive and had no cytopathic effect on the host cell for up to seven days. It has been reported that this situation can lead to the escape of bacteria from the immune system and to long-term infections [20]. Various mechanisms have been reported in the literature regarding the transmission and action mechanisms of bacteria to the nervous system. Grab et al. reported that with the in vitro blood brain barrier model containing microvascular endothelial cells of the human brain, the passage of bacteria through the barrier depends on the ability of the bacteria to affect the $\mathrm{Ca}++$ signaling system in endothelial cells [21]. Cepok et al. reported that the early stage of $B$. burgdorferi meningoradiculitis is characterized by a well-coordinated immune response involving specific cytokine release and plasma cell uptake, followed by a prolonged, antigenspecific B cell response in the central nervous system [22]. In the study of Rupprecht et al, it has been reported that chemokines (CXCL13) play a key role in attracting other immune cells to the inflammatory focus in Lyme neuroborreliosis, B cell migration to infection sites [23]. In the animal study of Pachner et al., Cytokines such as IL-6 have been reported to be important amplification molecules for cerebrospinal fluid inflammation in Lyme neuroborreliosis [24]. In Lyme disease, as a result of these changes in the central nervous system, it is expected that Lyme positivity in 
migraine patients is higher than in the control group. It has been reported that Lyme disease causes various neurological symptoms such as headache and $15 \%$ of patients have neurological involvement [25,26]. Chronic headache associated with Lyme disease is difficult to diagnose and can be confused with primary or analgesic overuse headaches. However, it is important to make the correct diagnosis because when this symptom is associated with borreliosis, it tends to regress with antibiotic therapy [27-30]. In the study of Scelsa et al., it was reported that the incidence of new-onset headache was $53.06 \%$ and the incidence of migraine was $18.37 \%$ among patients hospitalized for recurrent neurological Lyme disease. In addition, it has been reported that all patients with meningitis or encephalitis requiring intravenous antibiotics have not only headache but also focal neurological findings or cognitive abnormalities [28]. In the current study, the migraine and control groups were similar in terms of Lyme disease frequency. However, few studies have investigated the possible relationship between Lyme disease and migraine. We believe it is very important to point out that the initial design and strength of the study may not be sufficient for such a posthoc analysis, and therefore we suggest that future studies should consider this possibility. The research has several limitations. One of its limitations is that the research is not community-based and has a single center. On the other hand, questioning the chronology of the onset of migraine and the positivity of these pathogens (Toxoplasma gondii, Borrelia burgdorferi) could enable us to see the relationship between migraine and the positivity of these pathogens more clearly. Despite these, this study is valuable because it is one of the few studies evaluating the relationship between migraine and Lyme disease and it shares results that support the relationship between Toxoplasma gondii and migraine.

\section{Conclusion}

In terms of the infections studied in the study group, there was statistically significant difference was found between patients with migraine and controls. However, further studies that enable comparisons by ensuring an infection distribution similar to that of the population are required.

Funding: The author(s) received no financial support for the research, authorship, and/or publication of this article.

Conflict of Interest: The authors declare that they have no conflict of interest.

Ethical statement: The study was approved by the Local Ethics Committee of University (Date: 13/10/2020, approval number: 2020/245), and written informed consent was obtained from each subject.

\section{Open Access Statement}

This is an open access journal which means that all content is freely available without charge to the user or his/her institution under the terms of the Creative Commons Attribution NonCommercial License (http://creativecommons.org/licenses/bync/4.0). Users are allowed to read, download, copy, distribute, print, search, or link to the full texts of the articles, without asking prior permission from the publisher or the author.

\section{References}

[1]Stovner L, Hagen K, Jensen R, et al. The global burden of headache: a documentation of headache prevalence and disability worldwide. Cephalalgia. 2007; 27(3):193210. 
[2]Society HCCOTIH. The international classification of headache disorders, (beta version). Cephalalgia. 2013; 33(9):629-808.

[3]Schoonman GG, Schytz HW, Ashina M. Migraine trigger factors. Oxford Textbook of Headache Syndromes. 2020:67.

[4]Ferrigno G, Mazza M, Morelli M, et al. Chronic migraine as unusual presentation of syphilis. Xlvii Congresso Nazionale 22-25 Ottobre 2016 - Venezia.

[5]Nayeri T, Sarvi S, Moosazadeh M, Hosseininejad Z, Amouei A, Daryani A. Association between Toxoplasma gondii infection and headache: a systematic review and meta-analysis. Infect Disord Drug Targets. 2020.2 doi: 10.2174/1871526520666200617135851.

[6]Koseoglu E, Yazar S, Koc I. Is Toxoplasma gondii a causal agent in migraine? Am J Med Sci. 2009;338(2):120-22.

[7]Feder HM Jr. Lyme disease in children. Infect Dis Clin North Am. 2008;22(2):315-26.

[8]Centers for Disease Control and Prevention. Lyme Disease: Diagnosis and Testing. CDC. Available

at http://www.cdc.gov/lyme/diagnosistestin g/LabTest/TwoStep/index.html. November 20, 2019; Accessed: March 30, 2021.

[9]Flegr J. Neurological and neuropsychiatric consequences of chronic Toxoplasma infection. Curr Clin Micro Rpt. 2015; 2(4):163-72.

[10]Abo-Al-Ela HG. Toxoplasmosis and Psychiatric and Neurological Disorders: A Step toward Understanding Parasite Pathogenesis. ACS Chem Neurosci. 2020 Aug 19;11(16):2393-2406.

[11]Tedford E, Mcconkey G. Neurophysiological changes induced by chronic Toxoplasma gondii infection. Pathogens. 2017; 6(2):19.
[12] Prandota J, Gryglas A, Fuglewicz A, et al. Recurrent headaches may be caused by cerebral toxoplasmosis. World $\mathrm{J}$ Clin Pediatr. 2014;3(3):59-68.

[13]Akturk HK, Sotello D, Ameri A, et al. Toxoplasma Infection in an Immunocompetent Host: Possible Risk of Living with Multiple Cats. Cureus. 2017;9(3):e1103.

[14]Prandota J. Recurrent headache as the main symptom of acquired cerebral toxoplasmosis in nonhuman immunodeficiency virusinfected subjects with no lymphadenopathy: the parasite may be responsible for the neurogenic inflammation postulated as a cause of different types of headaches. Am $\mathbf{J}$ Ther. 2007; 14(1):63-105.

[15] Alvarado-Esquivel C, Del Rosario RicoAlmochantaf Y, Sanchez-Anguiano LF, et al. Toxoplasma gondii Infection and Headache: A Matched Case-Control Study in a Public Hospital in Durango City, Mexico. J Clin Med Res. 2018; 10(1):27-31. [16] Schlüter D, Däubener W, Schares G, et al. Animals are key to human toxoplasmosis. Int J Med Microbiol. 2014; 304(7):917-29.

[17] Mendez OA, Koshy AA. Toxoplasma gondii: Entry, association, and physiological influence on the central nervous system. PLoS Pathog. 2017; 13(7):e1006351.

[18] Silva CS, Neves Ede S, Benchimol EI, et al. Postnatal acquired toxoplasmosis patients in an infectious diseases reference center. Braz J Infect Dis. 2008; 12(5):438-41.

[19]Kazak E, Helvaci NY, Helvaci S. Nöroborrelyoz. Uludağ Üniversitesi T1p Fakültesi Dergisi. 2013; 39(2):137-45.

[20]Livengood JA, Gilmore RD. Invasion of human neuronal and glial cells by an infectious strain of Borrelia burgdorferi. Microbes Infect. 2006; 8(14-15):2832-40. 
[21]Grab DJ, Nyarko E, Nikolskaia OV, et al. Human brain microvascular endothelial cell traversal by Borrelia burgdorferi requires calcium signaling. Clin Microbiol Infect. 2009; 15(5):422-26.

[22] Cepok S, Zhou D, Vogel F, et al. The Immune Response at Onset and During Recovery From Borrelia burgdorferi Meningoradiculitis. Arch Neurol. 2003; 60(6):849-55.

[23] Rupprecht TA, Plate A, Adam M, et al. The chemokine CXCL13 is a key regulator of $\mathrm{B}$ cell recruitment to the cerebrospinal fluid in acute Lyme neuroborreliosis. J Neuroinflammation. 2009;6:42.

[24]Pachner A, Amemiya K, Delaney E, et al. Interleukin-6 is expressed at high levels in the CNS in Lyme neuroborreliosis. Neurology. 1997; 49(1):147-52.

[25]Rauer S, Kastenbauer S, Fingerle V, et al. Lyme neuroborreliosis. Deutsches Ärzteblatt International. 2018; 115(45):751.

[26]Marques AR. Lyme neuroborreliosis. CONTINUUM: Lifelong Learning in Neurology. 2015; 21(6):1729-44.

[27] Kowacs PA, Martins RT, Piovesan EJ, et al. Chronic unremitting headache associated with Lyme disease-like illness. Arq Neuropsiquiatr. 2013;71(7):470-73.

[28] Scelsa SN, Lipton RB, Sander H, Herskovitz S. Headache characteristics in hospitalized patients with Lyme disease. Headache. 1995;35(3):125-30.

[29]Brinck T, Hansen K, Olesen J. Headache resembling tension-type headache as the single manifestation of Lyme neuroborreliosis. Cephalalgia. 1993; 13(3):207-9.

[30] Moses JM, Riseberg RS, Mansbach JM. Lyme disease presenting with persistent headache. Pediatrics. 2003; 112(6):e477-e9. 